\title{
EL DIVORCIO SIN EXPRESIÓN DE CAUSA EN MÉXICO
}

\section{NO-FAULT DIVORCE IN MEXICO}

Alejandro de la Fuente Alonso ${ }^{1}$

\section{RESUMEN}

La familia ha dejado de ser la unidad básica de la sociedad, la evolución en materia de Derechos humanos nos ha llevado a la priorización de la protección de los derechos de los grupos vulnerables y de principios inherentes a la naturaleza del ser humano como es el de libre desarrollo de la personalidad. Existen diversas legislaciones que contemplan esta vía incausada para concluir el vínculo matrimonial, algunas aún no han integrado como lex lata esta posibilidad pero ante el criterio de nuestro máximo tribunal se convierte en un derecho exigible vía juicio de protección de derechos humanos. Para poder cumplir con el texto del artículo primero Constitucional de garantizar los Derechos Humanos es necesario otorgar el acceso a la justicia oportuna a todos los mexicanos a través de la inclusión del divorcio incausado en la legislación familiar o civil según sea el caso.

Palabras clave: Sociología jurídica; Derecho Familiar; Divorcio incausado; Libre desarrollo de la personalidad; disolución vínculo matrimonial.

\begin{abstract}
The family is no longer the basic unit of society, the evolution in the sphere of human rights has led us to prioritize the protection of the rights of vulnerable groups and the principles inherent of human nature, such as the free development of personality. There are various laws that contemplate this way without cause to conclude the marriage bond, some have not yet integrated this possibility as lex lata but, at the discretion of our highest court, it becomes an enforceable right through a trial for the protection of human rights. In order to comply with the text of the first Constitutional article to guarantee Human Rights, it is necessary to grant timely access to justice to all Mexicans through the inclusion of divorce uncaused in family or civil legislation.
\end{abstract}

Keywords: Legal sociology; Family right; Divorce uncaused; Free development of personality; dissolution of marriage bond.

\footnotetext{
${ }^{1}$ Doctor en Derecho por la Universidad Nacional Autónoma de México - UNAM, Investigador de tiempo completo del Colegio de Vera Cruz, México. Contato principal para correspondência. Universidad Veracruzana - México. E-mail: dralejandrode@ hotmail.com
} 


\section{CONCEPTO DE DIVORCIO INCAUSADO}

Se debe hacer un análisis de la noción de divorcio incausado para que con ello se puedan establecer premisas y argumentos con respecto a la pertinencia o no pertinencia de la modalidad de divorcio en comento

Como se revisado parcialmente en apartados anteriores desde un punto de vista general, el divorcio se entiende como la "acción y efecto de divorciarse" acción que ha sido definida por el "dicho de un juez competente disolver, o separar por sentencia, el matrimonio, con cese efectivo de a convivencia conyugal". (SCJN, 2012)

El término Incausado gramaticalmente hablando, se compone del prefijo in, que a su vez indica "negación o privación" y la palabra causado, de causa, que entre sus sentidos tiene la de "motivo o razón para obrar". Esto implica que el divorcio incausado desde su significado semántico es la disolución del matrimonio sin razón alguna, esto pareciera ser una definición un tanto ilógica, para que fuera una definición correctamente elaborada se tendría de la siguiente manera: disolución del matrimonio sin razón jurídica alguna.

Es por lo que el "divorcio incausado" es la disolución del matrimonio que puede determinarse sin necesidad de que se exprese causal o motivo alguno desde un punto de vista jurídico. Este tipo de divorcio es conocido de muchas maneras, por ejemplo, se le denomina el divorcio exprés, debido a su agilidad con se lleva su tramitación, de la misma manera se le conoce como el divorcio por declaración unilateral, debido a solo se requiere la voluntad de una de las partes para que esta sea decretada.

Indistintamente de su dominación o nombre, el divorcio incausado debe de interpretarse como la posibilidad de que "cualquiera de las partes, puede solicitar al juez, la terminación de su matrimonio" siendo omiso en explicar las causas de su decisión o fundamentar tal acto jurídico.

Como lo señala el autor Bejarano Alfonso, el divorcio incausado "no depende del consentimiento de ambos cónyuges para obtener el divorcio, el simple deseo de uno de ellos pone fin al vínculo, lo quiera o no el otro es una determinación judicial cuyas consecuencias legales son la no continuación de una vida en común”. (SCJN, 2012)

En el mismo sentido Castañeda Rivas, al hablar del divorcio sin expresión de causa, refiere que es aquel en el que uno de los cónyuges ya sea el hombre o la mujer, unilateralmente, puede solicitar al juez el divorcio. (Castañeda, 2009) 
La primera sala de la Suprema Corte de Justicia de la Nación ha referido que el divorcio sin causa es aquel mediante el cual es requisito suficiente la solicitud unilateral de uno de los cónyuges para la disolución del matrimonio, con ello el juez la decreta aun sin causa jurídica para ello, no importando la posible oposición del consorte que no ha solicitado la disolución

Haciendo una revisión histórica, es importante destacar que en el derecho romano el affectio maritalis o la voluntad de ambos para continuar casados, era esencial en la relación conyugal y su desaparición era causa suficiente para la ruptura del vínculo. (Margadant, 1978)

En este sentido, los romanos consideraban que no debía subsistir un matrimonio si una de las partes se percataba de que esta figura del affectio había desaparecido, (Margadant, 1978) pues para ellos ya no existía el elemento básico del matrimonio: la libre voluntad de convivir honorablemente juntos.

El repudium, la cual es un antecedente del divorcio incausado en la época de la roma antigua, era una declaración unilateral de voluntad pues "en el sentido de no querer continuar unido en matrimonio". (Morineau, 2006) La sola manifestación de uno de los esposos, en la perspectiva de concluir con su matrimonio, era razón suficiente y válida, para disolver el vínculo matrimonial.

En esta misma línea de ideas, Según Marta Morineau y Román Iglesias, la forma de terminar el matrimonio unilateralmente, fue frecuentemente utilizada a partir de la época del emperador Augusto, sobre todo si la pareja no tenía hijos. (2006)

Por cuanto al divorcio incausado, se ha advertido que este tiene sus antecedentes desde el derecho romano, principalmente se destacaban las disoluciones conyugales siguientes:

a) Bona gratia: Este tipo de divorcio tiene relación al divorcio por mutuo consentimiento, pues la disolución de este obedece a la voluntad de los dos cónyuges.

b) Repudium sine nulla causa: Este tiene su origen en la declaración unilateral de la voluntad de alguno de los cónyuges, sin necesidad de que se discutiera una causa.

De esta manera, era el afecto conyugal y la voluntad de permanecer unidos, la base principal del connubio para los romanos, ellos sostenían que cuando faltaba alguno de estos elementos, el matrimonio debería dejar de existir. (Ferrer, 1979)

Es por esta razón que se remite al derecho Romano como claro antecedente del divorcio incausado, conforme a la cual, la disolución del vínculo conyugal puede tener lugar por si sola la voluntad de cónyuge y sin expresión de causa alguna. (Galindo, 2009)

En el año de 1969, en el estado de california, se promulgó una nueva ley de familia, la cual tuvo innovaciones, puesto que no se requiere de expresión de causa para pedir el divorcio, 
pues no es necesario probar alguna culpa, en este caso cualquiera de los cónyuges puede solicitar el divorcio.

Las compensaciones económicas no estaban sujetas a la culpa, en cuanto a los alimentos y a división de los bienes estos debían resolverse sin consideraciones de género.

En mayor o menor medida el divorcio fue adoptado por diferentes países como Australia en el año 1975, Uruguay en el año 1978, en nueva Zelanda en el año 1980, y en Nicaragua en el año 1988.

\section{NATURALEZA JURÍDICA DEL DIVORCIO Y DEL DIVORCIO INCAUSADO}

Previo a esgrimir argumentos a favor o en contra del divorcio incausado, se debe hacer una revisión de su esencia como figura jurídica, es decir determinar la naturaleza jurídica del mismo en virtud de su configuración como concepto de la ciencia jurídica.

La disolución del vínculo conyugal que, previa solicitud formulada, incluso, por uno solo de los cónyuges, puede ser decretada por la autoridad judicial, bastando para ello con que aquel manifieste su voluntad de dar por terminada el matrimonio, sin necesidad de invocar causa o motivo alguno y sin importar la posible oposición del otro cónyuge. Alguno de los elementos principales, dados en el divorcio incausado son:

i. La disolución del vínculo conyugal; Puesto que el divorcio incausado tiene la naturaleza de un divorcio vincular, es por lo que se caracteriza por la disolución del vínculo de los cónyuges, quienes, a su vez, al extinguir el matrimonio quedan en aptitud de contraer otro.

ii. La disolución es decretada por una autoridad judicial; Esta previsto que la autoridad competente será únicamente la autoridad judicial, es decir un juez de lo familiar, el cual tendrá competencia para decretar el mismo.

iii. La solicitud debe de interceder por uno o por ambos cónyuges; Para que esta solicitud sea conveniente se requiere que uno o que los dos cónyuges asistan ante la autoridad pertinente, para que sea decretada la disolución, es por ello que esta solicitud es ante la autoridad judicial, dado a obtener el reconocimiento judicial sobre la disolución matrimonial.

iv. Para que pueda decretarse la solicitud, basta con el que el interesado exprese su voluntad de querer disolver le vínculo conyugal; El cónyuge que desee disolver el vínculo matrimonial. 
Asimismo, para determinar la naturaleza jurídica del divorcio es menester hacer estudio de la naturaleza jurídica del matrimonio, si bien son dos figuras jurídicas distintas; son dos caras de una misma moneda, es decir, uno genera un vínculo matrimonial y el otro lo disuelve, pero al final de cuentas las dos instituciones tienen como finalidad la regulación de las relaciones familiares, así como la de los derechos y obligaciones de estos.

En esta línea de ideas se tiene que el divorcio tiene su naturaleza jurídica como un contrato, como un acto jurídico y como una institución. Cuando se habla del divorcio como un contrato, más bien se habla de la disolución o terminación del contrato, pues la celebración del contrato sería el matrimonio, como se puede advertir el elemento del contrato que impera tanto en el matrimonio como en el divorcio es el consentimiento de la relación, en este sentido cuando el consentimiento ya no existe o ya no se desea seguir con esa relación es cuando se da por terminado el matrimonio. (Martínez, 2013)

El divorcio como acto jurídico se debe clasificar como mixto pues no es un acto exclusivamente privado porque no solamente intervienen particulares, pero tampoco es un acto jurídico donde su naturaleza sea únicamente de carácter público. Es mixto porque se requiere de la participación de los cónyuges y de una autoridad estatal, en este caso del registro civil o de un juez de lo civil. (Martínez, 2013)

El divorcio como institución, se da en virtud de que el mismo posee un conjunto de reglas o normas de derecho de forma organizada. Al respecto Rojina Villegas menciona que una institución jurídica es: "un conjunto de normas de igual naturaleza que regulan un todo orgánico y persiguen una misma finalidad”. (Rojina, 2010) En consecuencia, si el divorcio tiene como finalidad regular la disolución matrimonial son menoscabar los derechos de los miembros de la familia, entonces el divorcio tiene la naturaleza jurídica de ser una institución.

En cuanto a la naturaleza jurídica del divorcio incausado, existe una problemática no sólo doctrinal sino de carácter práctico, por lo general un divorcio es un acto jurídico que todas luces es bilateral, pero cuando se aborda la modalidad del divorcio incausado o exprés surgen varias interrogantes, que las expresa la maestra María Leoba Castañeda Rivas:

Desafortunadamente el legislador capitalino generó un sistema divorcista, en base a una solicitud, por lo cual, quienes enseñamos esta materia, nos preguntamos ¿Cuál es la naturaleza jurídica del divorcio actual? ¿será un acto unilateral? ¿un repudio iniciado por el hombre o la mujer? ¿podría ser bilateral, cuando ambos lo promueven, o bien uno de ellos lo solicita y el otro, acepta la propuesta de acuerdo? Efectivamente existe una nebulosa para definir la naturaleza jurídica del mal llamado divorcio "express" o "incausado" o "unilateral". (2012, p. 81) 


\title{
EL DIVORCIO INCAUSADO Y EL DERECHO HUMANO AL LIBRE DESARROLLO DE LA PERSONALIDAD
}

El divorcio incausado se define como la disolución del vínculo matrimonial que no requiere comprobación alguna causa para su procedencia, basta que una o ambas partes lo soliciten ante un Juez para que se conceda. Si bien es cierto que su regulación no está prevista dentro del articulado del código civil para el Estado de Veracruz, también lo es que a través de la actividad jurisdiccional de órganos del Poder Judicial de la Federación se han emitido diversos criterios que integran los vacíos normativos del aludido código. El cual ha sido mencionado en el capítulo segundo.

Ahora bien, una de las consideraciones primordiales por la que se ha habilitado el divorcio incausado estriba en que el libre desarrollo de la personalidad se encuentra incluido el derecho a decidir sobre el matrimonio y su disolución, tal y como lo sustenta la tesis 1a. LIX/2015 (10a.), establecida por la Primera Sala de la Suprema Corte de Justicia de la Nación, de la Décima Época del Semanario Judicial de la Federación y su Gaceta, Tomo II, correspondiente al mes de febrero del dos mil quince, de epígrafe y contenido siguiente:

\begin{abstract}
DIVORCIO SIN EXPRESIÓN DE CAUSA. CONSTITUYE UNA FORMA DE EJERCER EL DERECHO AL LIBRE DESARROLLO DE LA PERSONALIDAD. En el divorcio sin expresión de causa, es suficiente la solicitud unilateral de la disolución del matrimonio para que el juez la decrete aun sin causa para ello, donde incluso no importa la posible oposición del diverso consorte, pues la voluntad del individuo de no seguir vinculado con su cónyuge es preponderante, la cual no está supeditada a explicación alguna, sino simplemente a su deseo de ya no continuar casado, por lo que la sola manifestación de voluntad de no querer continuar con el matrimonio es suficiente. Así, dicha manifestación constituye una forma de ejercer el derecho al libre desarrollo de la personalidad, pues decidir no continuar casado y cambiar de estado civil, constituye la forma en que el individuo desea proyectarse y vivir su vida; es decir, el modo en que decide de manera libre y autónoma su proyecto de vida.
\end{abstract}

En consecuencia, el divorcio incausado puede establecerse como: La disolución del vínculo conyugal, previa solicitud formulada, incluso, por uno solo de los cónyuges, puede ser decretada por la autoridad judicial, bastando para ello conque aquél manifieste su voluntad de dar por terminado el matrimonio, sin necesidad de invocar causa o motivo alguno y sin importar la posible oposición del otro cónyuge.

Como se puede advertir el divorcio sin expresión de causa tiene su fundamento en el derecho humano a libre desarrollo de la personalidad. En cuanto a los derechos humanos que pudieran tutelarse dentro del divorcio incausado se encuentra el derecho a la libre personalidad, 
la cual está regulada en la tesis P. LXVI/2009, sustentada por la Primera Sala de la Suprema Corte de Justicia de la Nación, de la Novena Época del Semanario Judicial de la Federación y su Gaceta, Tomo XXX, correspondiente al mes de diciembre del dos mil nueve, de epígrafe y contenido siguiente:

\begin{abstract}
DERECHO AL LIBRE DESARROLLO DE LA PERSONALIDAD. ASPECTOS QUE COMPRENDE. De la dignidad humana, como derecho fundamental superior reconocido por el orden jurídico mexicano, deriva, entre otros derechos personalísimos, el de todo individuo a elegir en forma libre y autónoma su proyecto de vida. Así, acorde a la doctrina y jurisprudencia comparadas, tal derecho es el reconocimiento del Estado sobre la facultad natural de toda persona a ser individualmente como quiere ser, sin coacción ni controles injustificados, con el fin de cumplir las metas u objetivos que se ha fijado, de acuerdo con sus valores, ideas, expectativas, gustos, etcétera. Por tanto, el libre desarrollo de la personalidad comprende, entre otras expresiones, la libertad de contraer matrimonio o no hacerlo; de procrear hijos y cuántos, o bien, decidir no tenerlos; de escoger su apariencia personal; su profesión o actividad laboral, así como la libre opción sexual, en tanto que todos estos aspectos son parte de la forma en que una persona desea proyectarse y vivir su vida y que, por tanto, sólo a ella corresponde decidir autónomamente.
\end{abstract}

De igual manera cuando dentro del matrimonio, que se va a disolver, si existen hijos se tutela el derecho del interés superior del menor, esto es sustentado en la jurisprudencia 1a./J. 25/2012 (9a.), por la Primera Sala de la Suprema Corte de Justicia de la Nación, de la Décima Época del Semanario Judicial de la Federación y su Gaceta, Tomo I, correspondiente al mes de diciembre del dos mil doce, de epígrafe y contenido siguiente:

INTERÉS SUPERIOR DEL MENOR. SU CONCEPTO. En términos de los artículos 4o., párrafo octavo, de la Constitución Política de los Estados Unidos Mexicanos; 3 de la Convención sobre los Derechos del Niño, ratificada por México y publicada en el Diario Oficial de la Federación el 25 de enero de 1991; y 3, 4, 6 y 7 de la Ley para la Protección de los Derechos de Niñas, Niños y Adolescentes, los tribunales, en todas las medidas que tomen relacionadas con los menores, deben atender primordialmente al interés superior del niño; concepto que interpretó la Corte Interamericana de Derechos Humanos (cuya competencia contenciosa aceptó el Estado Mexicano el 16 de diciembre de 1998) de la siguiente manera: "la expresión 'interés superior del niño' ... implica que el desarrollo de éste y el ejercicio pleno de sus derechos deben ser considerados como criterios rectores para la elaboración de normas y la aplicación de éstas en todos los órdenes relativos a la vida del niño".

En el Estado Mexicano se han dado una serie de Reformas Constitucionales que sirven de fuente y fundamento a la legislación. Principalmente se hará énfasis en la reforma del 11 de junio del año 2011 en materia de Derechos Humanos. Además, nuestro máximo órgano, la Suprema Corte de Justicia de la Nación, como se ha revisado, ha emitido jurisprudencia relativa a la protección y efectividad de los derechos fundamentales que permea al ordenamiento jurídico mexicano. Es necesario hacer una revisión de los numerales constitucionales relativos 
a los derechos de familia, pues estos mismos deben de estar estrechamente relacionados con la configuración del divorcio y del divorcio incausado, tema principal del presente trabajo de investigación.

El artículo referido a los derechos humanos en general es el artículo primero de la Constitución Política de los Estados Unidos Mexicanos (CPEUM) el cual afirma:

\begin{abstract}
Artículo 1o. En los Estados Unidos Mexicanos todas las personas gozarán de los derechos humanos reconocidos en esta Constitución y en los tratados internacionales de los que el Estado Mexicano sea parte, así como de las garantías para su protección, cuyo ejercicio no podrá restringirse ni suspenderse, salvo en los casos y bajo las condiciones que esta Constitución establece.

Las normas relativas a los derechos humanos se interpretarán de conformidad con esta Constitución y con los tratados internacionales de la materia favoreciendo en todo tiempo a las personas la protección más amplia.

Todas las autoridades, en el ámbito de sus competencias, tienen la obligación de promover, respetar, proteger y garantizar los derechos humanos de conformidad con los principios de universalidad, interdependencia, indivisibilidad y progresividad. En consecuencia, el Estado deberá prevenir, investigar, sancionar y reparar las violaciones a los derechos humanos, en los términos que establezca la ley.
\end{abstract}

Como se puede advertir, la base constitucional es muy clara en cuanto al respeto y protección de los derechos humanos, donde estos derechos no pueden suspender y solamente se pueden restringir bajo ciertos supuestos especificados en la misma constitución. Todas las autoridades tienen la obligación para que exista el cumplimiento y protección de los derechos humanos.

En esta tesitura se debe aclara que los derechos humanos se deben de reconocer y proteger, situación que generó confusión pues previo a la reforma del 2011 se titulaba las garantías individuales, tal y como lo explicaron los Tribunales Colegiados de Circuito:

Época: Décima Época

Registro: 2008815

Instancia: Tribunales Colegiados de Circuito

Tipo de Tesis: Jurisprudencia

Fuente: Gaceta del Semanario Judicial de la Federación

Libro 17, Abril de 2015, Tomo II

Materia(s): Constitucional

Tesis: XXVII.3o. J/14 (10a.)

Página: 1451

DERECHOS HUMANOS Y SUS GARANTÍAS. SU DISTINCIÓN.

Antes de las reformas constitucionales de 6 y 10 de junio de 2011, las voces "derechos humanos y sus garantías", eran términos que solían confundirse, ambigüedad que posiblemente derivaba de la anterior denominación del capítulo I de la Constitución Política de los Estados Unidos Mexicanos, titulado "De las garantías individuales". Sin embargo, el Poder Reformador de la Constitución, con las citadas reformas, elevó a rango constitucional su distinción, como deriva de las siguientes menciones: i) el capítulo I cambió su denominación a "De los 
derechos humanos y sus garantías"; ii) en el artículo 1o. se especificó que todas las personas gozarán de los derechos humanos reconocidos en la Constitución y en los tratados internacionales "así como de las garantías para su protección", y iii) en el numeral 103, fracción I, se especificó que los Tribunales de la Federación resolverán toda controversia que se suscite por infracción a los derechos humanos y las "garantías otorgadas para su protección". Luego, para el Constituyente Permanente los derechos y sus garantías no son lo mismo, ya que éstas se otorgan para proteger los derechos humanos; constituyen, según Luigi Ferrajoli, los "deberes consistentes en obligaciones de prestación o en prohibiciones de lesión, según que los derechos garantizados sean derechos positivos o derechos negativos", es decir, son los requisitos, restricciones, exigencias u obligaciones previstas en la Constitución y en los tratados, destinadas e impuestas principalmente a las autoridades, que tienen por objeto proteger los derechos humanos; de ahí que exista una relación de subordinación entre ambos conceptos, pues las garantías sólo existen en función de los derechos que protegen; de tal suerte que pueden existir derechos sin garantías pero no garantías sin derechos. Así, a manera de ejemplo, puede decirse que el derecho humano a la propiedad tiene, entre otras garantías, las de audiencia y legalidad, pues prohíbe a la autoridad molestar a un particular sin mandamiento escrito en el que funde y motive la causa legal del procedimiento, y que los gobernados sean privados de la propiedad sin previa audiencia.

Como se puede observar, las garantías son mecanismos jurídicos que tienen por objeto hacer efectivos los derechos humanos. En consecuencia, las autoridades deben velar y garantizar la protección de los derechos humanos bajo la garantía que sea la más adecuada y pertinente, incluyendo como se mencionará más adelante la protección de la familia.

El otro artículo constitucional que tiene como base la protección de la familia es el cuarto, pues en el se le otorga la función principal al Estado de la protección de la familia, tal y como se redactó por el Constituyente:

Artículo 4o. El varón y la mujer son iguales ante la ley. Esta protegerá la organización y el desarrollo de la familia.

Toda persona tiene derecho a decidir de manera libre, responsable e informada sobre el número y el espaciamiento de sus hijos.

Toda persona tiene derecho a la alimentación nutritiva, suficiente y de calidad. El Estado lo garantizará.

En este sentido se tiene una protección del desarrollo y organización de la familia, adicionalmente se le brinda atención especial al derecho de alimentos y sobre los hijos como parte del catálogo de derechos de familia.

Por otro, ya se ha mencionado el interés superior del menor, que además de su protección de carácter jurisprudencial cuenta con una base constitucional:

En todas las decisiones y actuaciones del Estado se velará y cumplirá con el principio del interés superior de la niñez, garantizando de manera plena sus derechos. Los niños y las niñas tienen derecho a la satisfacción de sus necesidades de alimentación, salud, educación y sano esparcimiento para su desarrollo integral. Este principio deberá guiar el diseño, ejecución, seguimiento y evaluación de las políticas públicas dirigidas a la niñez. 
Los ascendientes, tutores y custodios tienen la obligación de preservar y exigir el cumplimiento de estos derechos y principios.

El Estado otorgará facilidades a los particulares para que coadyuven al cumplimiento de los derechos de la niñez.

Como se observa son variados los derechos de familia, se debe de recalcar que el presente tema es el divorcio incausado y que la relación que guarda con los derechos de familia son estrechos, pues tanto matrimonio como divorcio son figuras jurídicas que tienen una relación directa. Pues el divorcio guarda su eficiencia en virtud de que se sigan respetando los derechos de familia y se sigan cumpliendo aún si los cónyuges disolvieron el vínculo matrimonial.

\section{PERTINENCIA O NO PERTINENCIA DEL DIVORCIO INCAUSADO}

Después de haber analizado desde el concepto del divorcio incausado hasta su marco teórico, ahora se establecerán los problemas que, desde la perspectiva de esta investigación, se encuentran en la temática y son los siguientes:

I. Suprime la necesidad de acreditar una causal para solicitar el divorcio y permite la disolución del vínculo matrimonial mediante la solicitud de solo uno de los cónyuges sin que el otro pueda, de alguna forma, oponerse a la disolución.

II. Se hace notable que dicha reforma instituye un proceso que viola la garantía de audiencia contenida en el segundo párrafo del artículo 14 de la Constitución Política de los Estados Unidos Mexicanos al no permitir al cónyuge que no haya solicitado el divorcio, recurso o medida alguna para evitar la disolución matrimonial y la consiguiente afectación a su esfera jurídica.

III. El cónyuge que no presentó la solicitud de divorcio y que no desea la disolución del matrimonio, sufrirá por el acto de la privación consistente en la sentencia de divorcio, de forma definitiva e irreparable las consecuencias de dicha disolución, es decir, la modificación de su estado civil y los derechos que le derivan del matrimonio.

IV. Hoy en día al promover el divorcio incausado y al actualizarse alguna causal de divorcio y al no existir ya las figuras de cónyuge inocente y cónyuge culpable se afecta la esfera jurídica del cónyuge inocente.

El divorcio incausado produce una afectación y un posible daño moral en el cónyuge que no lo solicitó, quedando en un estado de indefensión, lo que se resolvería estableciendo los códigos civiles dentro del capítulo de divorcio un articulado que salvaguarde la integridad tanto moral como económica y todas las consecuencias negativas derivadas del divorcio incausado. 
Impulsado conforme a un interés propio y cuya investigación es necesaria, puesto que en la figura del divorcio incausado se puede estimar efectos positivos y negativos, positivos en el sentido de que el trámite para disolver un matrimonio era muy pesado, caro y lento motivo por lo que lo dejaban en paz, sin embargo, ahora con la figura del divorcio incausado el matrimonio se deshace en menor tiempo y sin tanto desgaste para los cónyuges.

Hay un efecto negativo cuando genera una afectación tanto como para la o el cónyuge quien no solicito el divorcio como para hijos menores si es que existen, como un daño moral e inclusive económico lo cual yo considero "ad hoc" investigar fundamentar la pertinencia y no pertinencia del divorcio sin expresión de causa.

Dentro de la doctrina, argumentan los autores en los que se sustenta para esta investigación como lo es María Leoba Castañeda quien argumenta que: "si bien es cierto que no se puede obligar a la persona alguna a continuar en alguna relación conyugal a fortiori es también una necesidad responsabilizar a quienes han contraído matrimonio a cumplir con los efectos de dicha acción jurídica frente a la sociedad, a los hijos, respecto de los bienes, y en general hacerse cargo de los deberes derivados de esa unión” (2012, p. 79). Esto conlleva pensar que el hecho de poder realizar el trámite de divorcio exprés no implica que el solicitante pueda deshacerse de las responsabilidades contraídas durante el matrimonio.

Asimismo, en el caso de la legislación argentina, donde también se tiene habilitado el divorcio incausado (donde con la introducción de los derechos humanos en su Constitución marcó la pauta también para dejar de un lado las causas objetivas para el divorcio) tiene como principal y único deber jurídico el de asistencia mutua entre los cónyuges sin la necesidad de que cuando se tramite el divorcio exista una razón jurídica por la cual se pueda solicitarla. (Herrera, 2010)

En el caso referido, el divorcio incausado mantiene una configuración de carácter jurisdiccional y no administrativos, es decir, quienes resuelven sobre los divorcios sin expresión de causa son los jueces y no las autoridades administrativas.

La legislación argentina, estipula que el divorcio sin expresión puede ser una petición unilateral o bilateral, dicho de otra manera, fundamenta los procedimientos en la situación de que una sola parte lo solicite y también explica los requisitos en caso de que ambas partes lo soliciten. (Herrera, 2010)

Indistintamente de cualquiera de las dos situaciones, lo que se debe presentar es una propuesta, es decir, a un futuro la disolución de vínculo matrimonial que consecuencias jurídicas traerá el divorcio con respecto a los integrantes de la familia, a esto en México se le conoce como convenio. 
Ahora bien, es necesario irse para atrás un poco en las reflexiones, en cuestión de la protección del derecho familiar pues se debe de partir del hecho de que la protección de la familia como unidad básica de la sociedad es un deber y una obligación compartida tanto del Estado como de la sociedad misma. En este sentido, el Estado debe crear y aplicar normas que se adecuen a la realidad social actual y que tenga como eje conductor la protección de la familia de una forma integral.

Así pues, para lograr lo anterior es necesario cambiar la conceptualización de lo que se conoce como justicia social, de decir, dejar de lado una postura ius filosófica positivista para acceder a una postura crítica como la de John Rawls, donde la perspectiva se centre en la conformación de las practicas sociales y la calidad de las formas de comunicación.

Pareciera extraño que cuando se habla de divorcio también se habla de familia y matrimonio, indiscutiblemente son figuras jurídicas estrechamente relacionadas que deben abordarse. En este sentido, para lograr una mayor comprensión de lo anterior, Ana Carolina Fascioli Álvarez menciona:

La vida familiar debe estar sometida a regulaciones legales que garanticen los derechos y libertades de todos sus miembros, pero además, sus vínculos, roles y prácticas cotidianas deben ser justos. Ello no implica afirmar que la vida familiar se reduzca a la justicia o que no podamos esperar mucho más de estas relaciones, sino que más bien, como sugiere Honneth, es un espacio a caballo entre el amor y la justicia. Asimismo, se sugieren algunas claves para pensar cuál sería una correcta intervención del Estado en la familia. (2017)

Esto viene a explicar que no solamente es necesaria la intervención del Estado, sino también una participación de la sociedad para la construcción adecuada de lo que es la justicia social.

La concepción de la sociedad política bajo la doctrina de Rawls propone un sistema social donde el eje principal es la familia, pues aquella es la base sobre la cual se cimenta la sociedad, al respecto se Fascioli argumenta:

Al concebir la sociedad política como un sistema de cooperación social que se
extiende en el tiempo, la vida reproductiva es relevante para su teoría de justicia,
porque ella garantiza la producción y reproducción ordenada de la sociedad y de
su cultura de una generación a la siguiente. La familia tiene un rol central para la
comunidad política en cuanto al cuidado y educación de los hijos, pues asegura
su desarrollo moral y su educación en la cultura y las virtudes necesarias para
sustentar las instituciones sociales y políticas [...] (2017)

Como se puede advertir, los elementos que el Estado cuida con respecto a la familia son la educación (ciudadana, moral y cultural), cuidado y desarrollo de los menores, así como la subsistencia. Como se sabe, el divorcio es la disolución del matrimonio, esta es una figura 
jurídica que es necesaria a partir de que una vez que los cónyuges se separan subsisten algunos derechos y obligaciones derivadas de la unión que ya se encuentra disuelta.

Muchas situaciones deben de resolverse y determinarse cuando ocurre un divorcio, entre ellas están: los bienes generados durante el matrimonio, los hijos, la patria potestad, guarda y custodia, solo por mencionar alguna. En este sentido, se visualiza cuestiones de carácter práctico, sobre el seguimiento y fortalecimiento del núcleo familiar.

Uno de los argumentos que se establecen para una postura en contra del divorcio sin expresión de causa es que viola garantías de legalidad y audiencia. Como se puede advertir parte del procedimiento del divorcio incausado consiste en la solicitud por escrito de uno de los cónyuges solicitando el divorcio, en donde se anexa una propuesta de convenio. Siendo lo anterior la base del mencionado proceso de disolución, dejando a la otra parte resolver los asuntos de la propuesta de convenio bajo la vía incidental. (Castañeda, 2010)

Esto deja bajo la perspectiva procesal, al cónyuge que no promovió el procedimiento en un estado de indefensión al dejarlo sin recurso o medio de impugnación alguno para combatirlo, pues al final de cuentas basta la voluntad unilateral para que quede disuelto el matrimonio, al respecto María Leoba Castañeda Rivas menciona:

Mas aún, las garantías de audiencia y legalidad se violentan en ese tipo de divorcio incausado, porque quien no lo solicita, carece de recurso, para combatir la sentencia o el auto-su naturaleza no está bien definida en la reforma que da por terminado el matrimonio. Si el solicitante hace una propuesta de convenio que le parezca adecuada a la otra parte, es posible que se convierta en un divorcio bilateral, y por tanto, se cuente con las bases para definir sobre alimentos, hijos, los divorciados y los efectos patrimoniales, entre otras cuestiones. De otra manera, independientemente de lo argumentado por quien no lo solicita, concurra o no a la audiencia, el vínculo quedara disuelto. (2010)

Con esto, se hace visible que ciertos derechos pudieran ser conculcados a la postre de la progresividad del derecho humano al libre desarrollo de la personalidad, en consecuencia, no solamente será tarea del legislador sino del juzgador el de ponderar que derecho es el que debe preferirse sobre el otro para que no exista vulneración de estos.

Por lo que se puede advertir, básicamente existen dos posturas doctrinarias encontradas, una que clama que el divorcio incausado como forma efectiva de la agilización del proceso judicial mientras que otros opinan que dichos cambios en la figura del divorcio no aseguran ni garantizan la protección de la familia, así como tampoco resuelven los problemas derivados del 
rompimiento de las parejas, cuestión y función principal que debe realizar el Estado frente a la temática de la familia. (Bartolini, 2012)

\section{LA PERTINENCIA DEL DIVORCIO INCAUSADO EN MÉXICO}

En el derecho Civil Mexicano, y en especial en el Estado de Veracruz, algunos doctrinarios denominan a esta institución como un "contrato", teniendo una modificación circunstancial dando para a una serie de reformas y jurisprudencia lo cual causo una modificación en este contrato y desde esta perspectiva causo una inclinación en la balanza de la justicia. Se encuentra con el interés y con la finalidad, de investigar las posibles afectaciones directas y no directas tanto económicas, sociales y morales que se presentan al solicitar el divorcio sin expresión de causa. Es con ello que puede establecer una perspectiva que en la medida de lo posible pueda ser integral y no solamente ofrezca un análisis exclusivo de las leyes, sino del contexto social en general.

La presente investigación relativa a la Pertinencia o no pertinencia del divorcio sin expresión de causa, tiene como referente la entidad federativa del estado de Veracruz a partir de la jurisprudencia emitida por la Suprema Corte de Justicia de la Nación, pues tiene como objeto demostrar que se han soslayado cuestiones fundamentales y que inciden directamente en un sector de la sociedad.

En todo el territorio mexicano, la protección de la familia como unidad básica de la sociedad es un derecho fundamental, el cual es Estado debe de crear leyes y políticas públicas donde se establezca esa protección. Pues la familia es una parte importante de la sociedad bajo las siguientes consideraciones:

En México, la familia toma especial relevancia no sólo por el $97.7 \%$ de la población que vive en hogares familiares, sino también porque los hogares han tenido un incremento del $15.4 \%$ en tan sólo ocho años. Datos de la Encuesta Nacional de Ingresos y Gastos de los Hogares 2008 (ENIGH), muestran que en el año 2000 existían un total de 23.2 millones de hogares, mientras que para el año 2008, se documentaron 26.7 millones de hogares. De estos, los hogares fundados sobre relaciones familiares constituyeron la mayoría, nueve de cada diez mexicanos residen en hogares de tipo familiar y, entre ellos, los más frecuentes son aún los hogares nucleares (65\%) (López, R. y S. Gaspar, 2010, p. 74). (Bartolini, 2012)

Estos datos que se muestran fundamentan parte de la importancia de crear normas que sean adecuadas a la protección de la familia, pues no sólo basta que exista un proceso rápido y ágil de divorcio, sino que efectivo en cuanto a la protección de los derechos familiares. Esta situación se acrecentó más, en virtud de que la relación de divorcios este aumentando de forma 
progresiva, pues con ello tanto el Estado como la sociedad deben de reflexionar sobre la situación y buscar soluciones en conjunto para la mejora integral del contexto social relativo a la familia.

Por cuanto hace a los Estados Unidos Mexicanos, fue el 3 de octubre del año 2008 cuando se publicó en la Gaceta Oficial del Distrito Federal, un decreto por el cual se reformaban el Código Civil y el de Procedimientos Civiles para el Distrito Federal, en el sentido de que suprimían las figuras del divorcio judicial por mutuo consentimiento y el necesario o contencioso, para establecer en su lugar, el divorcio incausado.

En virtud de lo anterior, al entrar en vigor esta nueva figura del divorcio, el cual fue declarado procedente, para disolver los matrimonios anteriores, a decir anteriores a la entrada en vigor la nueva reforma se expone la siguiente tesis:

\section{DIVORCIO SIN CAUSA. APLICACIÓN NO RETROACTIVA DE LA LEY A LOS MATRIMONIOS CELEBRADOS ANTES DE SU VIGENCIA (LEGISLACIÓN DEL DISTRITO FEDERAL).}

El artículo 266 del Código Civil para el Distrito Federal, reformado por el artículo primero del decreto publicado en la Gaceta Oficial del Distrito Federal de tres de octubre de dos mil ocho, en vigor al día siguiente de su publicación, establece que el divorcio podrá solicitarlo cualquiera de los cónyuges ante la autoridad judicial, manifestando su voluntad de no querer continuar con el matrimonio, sin que se requiera señalar la causa por la cual se solicita, siempre que haya transcurrido cuando menos un año desde la celebración del matrimonio. Ahora bien, la regulación jurídica del matrimonio intenta conjugar, por un lado, la necesidad de ser un instrumento al servicio de la autonomía de la voluntad de las dos personas que desean contraerlo y, por otro, la necesidad de someter esta autonomía de la voluntad a límites derivados del interés público y social que tiene el Estado en proteger la organización y el desarrollo integral de los miembros de la familia y en asegurar que las normas que les afectan estén orientadas a asegurar el respeto de su dignidad, así como de otros valores y principios constitucionales. Esta naturaleza propia de las normas reguladoras del matrimonio y del derecho de familia, impide aceptar que las partes pacten quedar completamente al margen de los cambios legislativos que repercutan en su status personal y, por lo mismo, no cabe sostener que exista un derecho adquirido para que el matrimonio contraído bajo una ley determinada subsista permanentemente, o para que su disolución sólo proceda por causas previstas en la ley vigente al momento de celebrarse, y debiendo dichas causas necesariamente apoyarse en hechos posteriores a la celebración del matrimonio, no puede decirse que al ser tomadas en cuenta, desde luego con posterioridad a la vigencia de la ley, sea dicha ley aplicada retroactivamente, pues dicha aplicación retroactiva existiría si se pretendiese que la disolución del matrimonio por una nueva causa, o sin ella, como sucede en la nueva ley, surtiera efectos hacia el pasado considerando disuelto el vínculo matrimonial desde antes de que iniciase la vigencia de la ley, lo que en materia de divorcio ni siquiera podría suceder, porque la sentencia es constitutiva, en el sentido de que el estado jurídico de divorciado sólo se adquiere a partir de que aquélla se pronuncia, y si el motivo para el divorcio, o sea, en el caso, la voluntad de uno de los cónyuges, se exterioriza y se pretende surta efectos con posterioridad a que 
la ley ha iniciado su vigencia, es inexacto que ésta se aplique retroactivamente.

De esta manera el divorcio cuando es solicitado, y una vez entrado en vigor la reforma legal por cuanto al divorcio incausado, será resuelta de manera procedente, sin importar que al momento de celebrarse el matrimonio se rija por reglas distintas.

El divorcio incausado prevé algunos requisitos como:

a) Conlleva la disolución del vínculo matrimonial.

b) Los cónyuges quedaran en aptitud de contraer nuevas nupcias.

c) El divorcio puede solicitarse a través de uno o de los dos cónyuges.

d) Se puede reclamar a través de una autoridad judicial.

e) La persona que lo solicite debe manifestar su voluntad de dar por terminado el matrimonio y no es necesario expresar la causa o motivo.

El divorcio incausado, es contemplado en la República Mexicana, el primero en implementarlo fue el Distrito Federal, para posteriormente incorporarlo cuatro estados de la República, Coahuila, Estado de México, Guerrero y Yucatán también denominado unilateral o sin expresión de causa, mediante el divorcio incausado se elimina el divorcio necesario y se suprimen todas las causales que lo fundamentan: desaparece la figura del cónyuge culpable y el divorcio se decreta sin mayor trámite, aparentemente quedan pendientes para resolución posterior, vía incidental las consecuencias derivadas del mismo, porque en realidad el divorcio incausado constituye una unidad y esta etapa en realidad es de desahogo de pruebas, etapa incidental contemplada en el Distrito Federal, Guerrero y Yucatán, en resolución posterior pero no en vía incidental sino con todos los requisitos de una demanda el Estado de México y Coahuila.

Es de señalar que antes de lo que hoy se conoce como divorcio incausado, México ya contaba con una de sus variantes, como lo era el divorcio voluntario, en el que no se necesitaba expresar causal alguna para su procedencia, bastando el acuerdo de voluntades de los divorciantes y que se cumplieran los requisitos de ley.

En la legislación del Distrito Federal y Coahuila se regulan dos formas de divorcio dentro del mismo incausado:

1. Existe acuerdo de voluntades (divorcio consensuado) los cónyuges presentan la solicitud de divorcio acompañada del convenio.

2. No hay acuerdo de voluntades, a la solicitud de divorcio se acompaña la "propuesta de convenio", hay intervención judicial, el demandado puede no contestar, presentar su 
"contrapropuesta o allanarse a la propuesta de convenio", el divorcio se decreta de plano y sus consecuencias deben resolverse en la continuación del divorcio.

No obstante, de lo anterior, al menos cuando se implementó el divorcio incausado en el Distrito Federal (ahora Ciudad de México), en el convenio se pide poner algunos elementos a considerar, que son inherentes con respecto al divorcio:

1. La designación de la persona que tendrá la guarda y custodia de los hijos menores o incapaces. 2. Las modalidades por las cuales, el progenitor, que no tenga la guarda y custodia, ejercerá el derecho de visitas. 3. El modo de atender las necesidades de los hijos, especificando la forma, lugar y fecha de pago de la obligación alimentaria, así como la garantía para asegurar su debido cumplimiento. 4. Designación del cónyuge al que corresponderá el uso del domicilio conyugal, en su caso, y del menaje. 5. La manera de administrar los bienes de la sociedad conyugal durante el procedimiento y hasta que se liquide. 6 . Si se celebró el matrimonio bajo el régimen de separación de bienes deberá señalarse la compensación, que no podrá ser superior al 50\% del valor de los bienes que hubieren adquirido, a que tendrá derecho el cónyuge que, durante el matrimonio, se haya dedicado al desempeño del trabajo del hogar y, en su caso, al cuidado de los hijos o que no haya adquirido bienes propios o habiéndolos adquirido, sean notoriamente menores a los de la contraparte. El Juez de lo Familiar resolverá atendiendo las circunstancias especiales de cada caso. (Bartolini, 2012)

Esto quiere decir que, el divorcio incausado, resuelve de forma unilateral la disolución matrimonial y que los demás temas como bienes, pensión alimenticia, guarda y custodia, convivencia entre otros se resuelven de forma incidental, cuestión que como se ha visto desprotege al cónyuge que no solicitó el divorcio.

Parte de la implantación del divorcio incausado en México tuvo como argumento la rapidez en tiempo de dicho trámite, con ello se tiene que si se analiza solo bajo esta premisa de rapidez el divorcio incausado si cumple con ello. No obstante, ese no es el problema de fondo pues la obligación del Estado es la protección de la familia, no la rapidez de los trámites de divorcio.

Una institución tan polémica como lo es el divorcio incausado puede encontrar varias posturas dependiendo del autor, maestro o doctrinario. Como, por ejemplo:

Se tiene que Aníbal Guzmán Ávalos y María del Carmen Valdés Martínez opinan que:

El matrimonio es la institución por excelencia para constituir una familia, cuyo fin es la ayuda mutua, el socorro, la convivencia, la cohabitación, etcétera, y el Estado ha realizado todos los medios para protegerlo y preservarlo, sin embargo, tampoco puede cerrar los ojos ante aquellas situaciones en donde esos fines ya no se cumplen y los esposos deciden disolver el vínculo matrimonial que los une cuando se vuelve desafortunado.

Esta figura tiene un largo camino en nuestro país, y, como se pudo observar, ha tenido una larga evolución hasta llegar al divorcio incausado que se regula en el Código Civil para el Distrito Federal, que es una composición entre el divorcio necesario y divorcio voluntario en vía judicial, estableciendo un procedimiento 
expedito en el cual no se tiene que probar ya ninguna causa que origine el rompimiento matrimonial, con la sola manifestación de voluntad de no querer continuar con el matrimonio, y puede proponerse unilateral o bilateralmente. (2012)

Esta es una postura moderada, por otro lado, una postura en contra es la siguiente:

Como se advirtió, el divorcio exprés lejos de beneficiar a la familia perjudica a la mujer y sus hijos, además de que no reduce el costo y los tiempos para la resolución de los temas que verdaderamente les angustia, que consisten principalmente en la preocupación por los hijos y la situación económica.

Esto sin contar las múltiples inconsistencias y contradicciones procesales que presenta la referida reforma de divorcio exprés, algunas de las cuales se han descrito en el cuerpo de este análisis. (Bartolini, 2012)

No solamente existe una falta de consenso entre los autores mexicanos sino también en otras partes del mundo, por ejemplo, en Beatriz Martínez Cordero hace una publicación haciendo una comparativa entre la República Dominicana y Puerto Rico, donde en el primer país si hay un divorcio exprés denominándolo "al vapor" mientras que aduce que en su país existe un divorcio con expresión, lo que hace que salvaguarden los derechos de la familia, al respecto menciona textualmente:

\begin{abstract}
Dentro de nuestro sistema político-constitucional, más que las parejas, el estado es quien ejerce su función de guardián de la institución del matrimonio que es la base de nuestro sistema social. El estado se convierte en el centinela no solo de la institución, sino además del fruto de esa relación que son los hijos, los bienes y las raíces que extiende esa institución hacia todos los órdenes económicos, políticos, sociales y morales de nuestra sociedad. No vislumbro que el pueblo puertorriqueño permita un divorcio rápido y menos anticipo que lo sea para que extranjeros nos visiten a esos únicos efectos. Lo que si siento es que a pesar de los cambios sociales y morales de nuestra gente aun creemos en lo que es moral $\mathrm{y}$ en lo que nos distingue como gente que cree en el matrimonio como algo necesario para la paz colectiva y para la paz nuestra con Dios. (Martinez, 2004)
\end{abstract}

\title{
CONCLUSIÓN
}

La familia ha dejado de ser la unidad básica de la sociedad, la evolución en materia de Derechos humanos nos ha llevado a la priorización de la protección de los derechos de los grupos vulnerables y de principios inherentes a la naturaleza del ser humano como es el de libre desarrollo de la personalidad.

Existen diversas legislaciones que contemplan esta vía incausada para concluir el vínculo matrimonial, algunas aún no han integrado como lex lata esta posibilidad pero ante el criterio de nuestro máximo tribunal se convierte en un derecho exigible vía juicio de protección de derechos humanos. 
La evolución de los Derechos humanos y la reforma del artículo primero de nuestra constitución hace realidad la progresividad de éstos en nuestro sistema jurídico.

\section{REFERENCIAS}

Bartolini Esparza, Marcelo, Vallejos Parás, Cecilia, Pérez Hernández, Cándido y González Gómez, Erik, (2012) "El divorcio exprés en México: una reforma que no atiende a las necesidades sociales”, Universidad La Salle, Núm. 1, vol. 1, México.

Castañeda Rivas, María Leoba, (2012) El divorcio sin causa rompe la organización de la familia y desprotege a sus miembros, Colección de Textos Jurídicos Universitarios, Jurídicas UNAM, México.

Castañeda Rivas, María Leoba, (2010) "El divorcio con causa versus "incausado" o acausal”, Revista cultura Jurídica, núm. 1, vol. 1, México.

Castañeda Rivas, Leoba (2009) "Injusticias para los miembros de la familia, con el divorcio "incausado" del Distrito Federal", Escenarios Visión propositiva de Mexico y el Mundo, núm. 1, vol.1, México.

Fascioli Álvarez, Ana Carolina, (2017) “¿Es la vida familiar relevante para la justicia social?”, Ideas y Valores, vol. 66, núm.163, México.

Ferrer, Francisco, (1979) Cuestiones de derecho civil. Familia y sucesiones, RubinzalCulzoni Editores, Argentina.

Galindo Garfias, Ignacio, (2009) Derecho Civil. Primer curso. Personas y Familia, 26 Ed, Porrúa, México.

Guzmán Avalos, Aníbal y Valdés Martínez, María del Carmen. Del matrimonio indisoluble al divorcio exprés del Distrito Federal, México, Revista IUS [en línea], 2012, vol.6, num.29, fecha de consulta 30 de octubre de 2018, sin última fecha de actualización, disponible en: $<$ http://www.scielo.org.mx/scielo.php?script=sci_arttext\&pid=S1870-

$21472012000100006 \& \operatorname{lng}=$ es\&nrm=iso>. ISSN 1870-2147, p92.

Herrera, Marisa, (2010) El régimen de divorcio incausado en el Código Civil y Comercial de la Nación, Editorial Marcela Mascotena, Argentina.

Margadant, Guillermo Floris, (1978) Derecho Romano Privado, 8a , ed. México, editorial. Esfinge, México.

Martínez Cordero, Beatríz, (2004) “Divorcio: Nuestra Institución vs. El Divorcio “al vapor””, Revista de Derecho Puerto Rico, núm.1, vol. 44, Puerto Rico.

Martínez Rodríguez, Wendy, (2013) Análisis sobre la aplicación del divorcio incausado en el Estado de México, Universidad Autónoma del Estado de México, Centro Universitario UAEM Amecameca, México. 
Morineau Iduarte, Marta e Iglesias Gonzales, Román, (2006) Derecho Romano, $4^{\text {a }}$ ed., Colección de Textos Jurídicos Universitarios, Oxford University Press, México.

Rojina Villegas, Rafael, (2010) Derecho Civil Mexicano, Tomo Segundo, Editorial Porrúa, México.

Suprema Corte De Justicia de la Nación, (2012) Temas Selectos de Derecho Familiar, Divorcio Incausado, México.

Trabalho recebido em 23 de outubro de 2019

Aceito em 04 de junho de 2020 